\title{
Our 3-year Experience of Stem Cell Use in Treatment of Deep Skin Burns
}

\author{
EV Zinovyev*1,2, VE Yudin ${ }^{3,4}$, MS Asadulaev ${ }^{1}$, DV Kostyakov ${ }^{5}$, AS Shabunin ${ }^{3,4}$, NV Smirnova ${ }^{3}$ and KF \\ Osmanov $^{1}$ \\ ${ }^{1}$ Ministry of Healthcare of the Russian Federation, Russia \\ ${ }^{2}$ Saint Petersburg I.I. Dzhanelidze Research Institute of Emergency Medicine, Saint Petersburg, Russia
}

${ }^{3}$ Saint Petersburg, Russia

${ }^{4}$ Institute of Macromolecular Compounds of RAS, Saint Petersburg, Russia

*Corresponding author: EV Zinovye, Ministry of Healthcare of the Russian Federation, Russia

\begin{tabular}{l}
\hline ARTICLE INFO \\
\hline Received: 幽 March 14, 2019 \\
Published: March 29, 2019 \\
\hline Citation: EV Zinovyev, VE Yudin MS \\
Asadulaev, DV Kostyakov, AS Shabunin, \\
NV Smirnova, KF Osmanov. Our 3-year \\
Experience of Stem Cell Use in Treat- \\
ment of Deep Skin Burns. Biomed J \\
Sci \& Tech Res 16(4)-2019. BJSTR. \\
MS.ID.002872.
\end{tabular}

ABSTRACT

The results of three-year research on the use of Allogeneic Mesenchymal Stem Cells of adipose tissue (AMSCs) in the treatment of skin burns of II-III degree are presented. in a complex with wounds dressing of nanofibers chitosan and copolyamide, hyaluronic acid. It was found that with surgical necrectomy, introduction of AMSCs and substitution of defects with natural polymer coatings, the healing time is reduced by $89 \%$ ( $p<$ 0.05 ). Isolated administration of MSC reduces the healing period by no more than $5 \%$ ( $p$ $>0.05$ ). The combined use of wounds dressings of nanofibers chitosan and copolyamide with MSC accelerates the regeneration process by $26 \%(\mathrm{p}<0.05)$, with the introduction of AMSCs accelerating the development of granulation tissue by the fifth day of observation by $83 \%(p<0.01)$. Joint use of wound coverings on the basis of hyaluronic acid with AMSCs is accompanied by an increase in the number of vessels of the microcirculatory bed in the defect area by $185 \%(\mathrm{p}<0.01)$.

Clinical evaluation of the effectiveness of drugs with stem cells - a gel for topical application and a suspension of MSC LC for injection administration demonstrate their ability to optimize regeneration in the burn zone. Application of gel with AMSCs reduces the duration of epithelialization of border (dermal) burns by 2.2-2.4 times, with the final healing period being reduced by $59 \%(\mathrm{p}<0.01)$ and the suppuration frequency by $30 \%$ $(\mathrm{p}<0.05)$. The introduction of a suspension of AMSCs into the zone of deep burn increases the frequency of engraftment of autografts, stimulates angiogenesis and proliferation of fibroblasts in the superficial and deep layers of the dermis. In the area of MSC administration, the LC perfusion level and the amplitude of blood flow fluctuation are twice as high as the values in the zones without the introduction of cells.

\section{Introduction}

In the Russian Federation, up to half a million patients suffering from burns are registered each year. Of these, around one in ten have deep lesions; in one in seven or eight, the burns cover an area, exceeding $20 \%$ of the body surface. Mortality for deep burns is about $15 \%$ with no tendency to decrease [1]. The treatment of patients with serious burns is one of the most difficult tasks of surgery. At present, a wide range of tools and techniques are available to combustologists (burn specialists); nevertheless, in the vast majority of the cases of burns (up to 99\%), various methods of skin grafting are still used for restoring the skin. Skin grafting is categorized according to the principle of its implementation, taking into account the type of grafts and flaps used [2]. There has been a gradual introduction of biotechnological restoration of the skin to treat burns both in the Russian Federation and abroad 
[2-4]. Autologous skin cells grown in vitro were first used by Medawar et al. [5,6] with subsequent development in studies on the transplantation of cultures of keratinocytes, fibroblasts, dermal equivalents, hysteobioplastic materials, and scaffolds (threedimensional matrices based on natural polymers with living cells, which undergo slow destruction or resorption) as well as cultures of allogeneic and autologous stem cells [2,7].

The development and application of artificial organs, tissues, and scaffolds are considered a priority for regenerative medicine. All of these methods accelerate reparative regeneration in the transplantation zone because of both the cellular elements (primarily the adipose tissue mesenchymal stem cells) and products of polymer degradation [8,9]. Stem cells are immature cell units capable of di- vision and differentiation into the specialized cells of various organs and tissues $[8,11]$. Based on the source, stem cells can be embryonic or tissue-specific (such as mesenchymal and epidermal stem cells). A characteristic of embryonic stem cells is their high differentiation potential and their ability to act as a source of virtually any type of body cell. However, there are a number of difficulties associated with obtaining embryonic stem cells including ethical restrictions [12,13]. In addition, controlling their status to avoid the risk of their degeneration into tumor formation also causes difficulties. Researchers are currently focusing on the possibility of using Mesenchymal Stem Cells (MSCs) isolated from sources, such as bone mar- row, adipose tissue, the liver, and the spleen. However, not all of these sources of MSCs are equally available; for example, obtaining red bone marrow stem cells requires aspiration biopsy, which is an invasive and quite painful procedure [14-17].

The most promising source for MSCs is adipose tissue, which provides a safe, superficial source of cell cultures [18-20]. Adipose tissue is widely distributed in the human body and is conveniently located for allowing a significant amount of Adipose Tissue Mesenchymal Stem Cells (ATMSCs) to be obtained in a singlestep procedure with low trauma. A single gram of adipose tissue can contain up to $2 \times 106$ cells, $90 \%$ of which are suitable for a heterogeneous population for in vitro cultivation and differentiation into cells of different lines including adipogenic, osteogenic, chondrogenic, and myogenic lines. ATMSCs are able to form ten times more colony-forming units than MSCs from bone marrow [6]. The unique immune profile of ATMSCs makes them attractive for transplantation. Because of their immunological characteristics, they show no expression of the main complex molecules of class II histocompatibility, so they are less immunogenic than other cell populations $[22,23]$.

In addition, ATMSCs have immunomodulatory properties that reduce the risk of graft rejection in graft versus host disease, and they exhibit genetic stability during long-term cultivation procedures [14,20,22-25]. AT- MSCs can also inhibit the proliferation of activated T-cytotoxic lymphocytes and regulate the production of proinflammatory cytokines by T-helpers [26-30]. Local and systemic routes of delivery of MSCs to the zone of tissue defect have been proposed. However, aspects of the administration of stem cells into the vascular bed remain controversial. When Muehlberg et al. [13] administered ATMSCs intravenously to mice with induced sarcoma, they observed an accumulation of these cells in the neoplasm, which accelerated the division of tumor cells $[22,31]$. Conversely, an in vivo study showed that ATMSCs expressed cytosine deaminase, which has a suppressive effect on tumor cells [32]. Allogeneic MSCs for therapeutic purposes can be used both in isolation and in combination. Studies of the joint transplantation of ATMSCs and Langerhans islets for the treatment of diabetes mellitus showed that the ATMSCs contributed effectively to the engraftment and revascularization of pancreatic donor islets $[9,33]$.

The results of all the studies described seem extremely promising for burns treatment. In addition, a number of authors believe that the efficiency of grafting can be improved by the combined use of ATMSCs and allo or xenoskin grafts when there is a deficit of donor resources [34,35]. ATMSCs have been shown to stimulate neovascularization in response to hypoxia [33]. Their angiogenic potential was demonstrated using a model of limb ischemia in animals; an intravenous administration of a suspension of stem cells resulted in accelerated tissue repair. Histological examination following the administration of ATMSCs confirmed an increase in the number of microvessels and a decrease in the atrophy of striated myocytes in the area where they were administered [10]. The possibility and feasibility of using ATMSCs and products based on them for treating serious burns has been studied by various researchers, including Peng Liu, A.I. Kolesnikova, K.V. Kotenko, Liang Xue, and others [15,36,37]. In particular, Kolesnikova et al. have proposed a regeneration composition that contains at least 105 cells/ml of human bone marrow MSCs. A disadvantage of this method is the use of human red bone marrow as the source of the stem cells, which requires a highly complex process. A cell preparation based on multipotent mesenchymal stromal cells has been developed for the treatment of radiation burns of the skin for local infiltrative admin- istration into the zone of the lesion [36].

Liu et al. have used an animal model to evaluate wound dressings containing MSCs [37]. A deep skin burn was reproduced in rats and treated using MSCs, comparing the outcome with the effect of using a collagen scaffold without stem cells. At the end of the first month of observation, there was contraction and a reduction in the area of the wound lesion by $50 \%$ in the animals treated with MSCs, whereas the reduction was only $20 \%$ in the group of animals without treatment. Histological studies demonstrated that the use of stem cells stimulated angiogenesis; at fourth week, biopsy samples of the wounds treated with MSCs showed a 21\% increase in the number of newly formed microvessels $(p<0.05)$ [38]. Xue et al. [37] injected MSCs isolated from bone mar- row into burn lesions in mice, resulting in a decrease by $38 \%$ of the wound surface area after one week $(p<0.05)$, with the total area of the burn decreasing 
by $68 \%$ by the end of second week $(\mathrm{p}<0.05)$ [15]. In addition, the administration of MSCs increased angiogenesis in the affected area. From these reports, it can be concluded that there is no consensus on the feasibility of using MSCs in burns treatment. This remains a matter of discussion and serves as an incentive for further research.

\section{Materials and Methods}

This study comprised two parts. The first tested ATMSCs in an animal model and the second involved clinical tests with burns patients. The animal experiment used 48 male rats weighing 230-250g. All manipulations were per- formed under inhalation anesthesia (using ether) and under aseptic conditions. Third-degree skin burns (ICD10) with an area of $10 \%$ of the body surface were produced using our own original method. Stem cells were isolated and cultivated from the subcutaneous fatty tissue of rats in the Polymeric Materials for Tissue Engineering and Transplantology Laboratory of Peter the Great St. Petersburg Polytechnic University. The fifth passage of the cells was used for administration in the experiments. The animals were divided into six groups according to the method of treatment. In group I, the agents were applied immediately after the burn; in groups II, III, IV, and V, this was preceded by necrectomy. Group VI, the control group, did not receive treatment. In group $\mathrm{I}, 4 \mathrm{ml}$ of a suspension of ATMSCs $(1 \times$ $10^{6}$ cells $/ \mathrm{ml}$ ) was administered 60 min after the burn by injection under the eschar (Figure 1). In groups II and III, necrectomy was performed and then $4 \mathrm{ml}$ of the ATMSC suspension was injected under the fascia of the back.

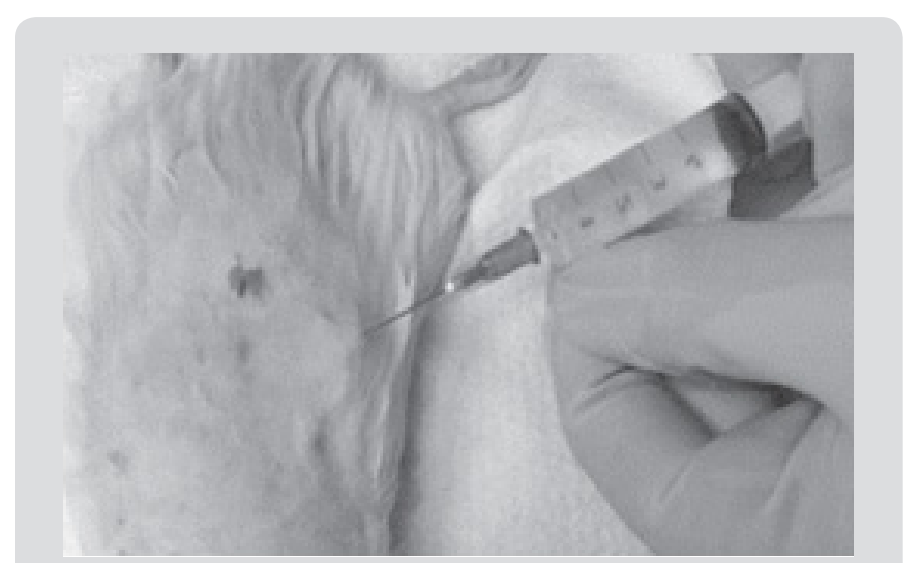

Figure 1: Stage of injection of a suspension of adipogenic mesenchymal stem cells subfascially in the area of skin burn of III degree.

The lesion was then closed with wound dressings based on either a hyaluronic acid hydrogel (G-group, Russian Federation) or chitosan- copolyamide (Institute of High Molecular Compounds of the Russian Academy of Sciences, Russian Fe- deration). The same wound dressings were used in groups IV and V, but without the prior administration of ATMSCs. In group VI, the control group, the wounds were not treated. The effectiveness of the treatment was evaluated daily. The wounds were inspected and photographed, and the nature of the discharge, the presence and type of granulations, any eschar rejection, and epithelization were recorded. The area of the wound was measured using the planimetric method of L.N. Popova, and the index of healing was calculated. Biopsy samples for histological examination were obtained on days $3,7,12,15,21$, 28 , and 60 . Paraffin sections were stained with hematoxylin and eosin and examined under light microscopy. The clinical part of the study included two stages to study the efficacy and safety of two biomedical cell products based on ATMSCs: Collagen-Cell Complex Product (CCCPTM) and Multipotent Mesenchymal Stromal Cells (MMSCTM).

The first preparation is a collagen biodegradable gel that includes a suspension of multipotent human mesenchymal stromal cells. The second preparation contains multipotent human mesenchymal stromal cells cultured in vitro in a total concentration of $(5.0+0.25) \times 106$ cells. The study included 30 patients with second- or third-degree der- mal burns, divided into three groups of 10 patients. In groups I and II, CCCPTM gel was applied twice at concentrations of either $0.05 \mathrm{ml} / \mathrm{cm}^{2}$ (group I) or $0.1 \mathrm{ml} / \mathrm{cm}^{2}$ (group II); in group III, the control group, Ointment Levomekol was applied instead. MMSCTM was administered twice to patients with severe burns after early necrectomy and simultaneous subfascial autodermografting around the perimeter of the wound, to the depth of the wound lesion, at equal distances from each other, fractionally, at $0.05 \mathrm{ml} / \mathrm{cm}^{2}$ of the wound area. This technique was approved by the local ethics committee. Objective and subjective data describing the patient's condition and laboratory parameters were repeatedly evaluated; these included the level of pain, thermometry, blood pressure, heart rate, total blood and urine analyses, and levels of glucose, bilirubin, alanine aminotransferase, aspartate aminotransferase, creatinine, and urea.

The healing time, frequency of wound suppuration, and degree of engraftment of skin grafts were recorded, and the wound surface area was measured by applying a planimetric method. In addition, a microbiological examination of the inoculation, histological examinations of biopsy samples, and a histochemical analysis of proliferation markers (EGFR, Ki 67) and apoptosis $\left(\mathrm{BCl}_{2}, \mathrm{p} 53\right)$ were performed. The condition of the wound after ATMSC transplantation was evaluated using Doppler flowmetry (LAKK Apparatus, Russian Federation). The results obtained were processed in accordance with generally accepted methods of variation statistics. A value of $p$ $<0.05$ was considered to indicate statistical significance.

\section{Results and Discussion}

Table 1 shows the timing of the final healing of the experimental wounds, compared between the six animal treatment groups. The wound healing time for the control group was 59 days, and the area of scarring at that time was $4.5 \mathrm{~cm}^{2}$. The fastest wound healing time, 44 days, was found in the group treated with necrectomy followed by the administration of ATMSC, supplemented with the application of wound dressings based on chitosan-copolyamide. The healing time was 15 days less than that for the control group ( $p<0.05)$. 
This group also showed the smallest area of scarring at day 60 (0.8 $\mathrm{cm}^{2}$ ). In comparison, the group that underwent necrectomy, the administration of ATMSC, and the application of wound dressings based on hyaluronic acid had a wound healing time of 47 days and an area of scarring on day 60 of $1.2 \mathrm{~cm}^{2}$. In the groups that did not Table 1: Planimetric evaluation of treatment results for experimental wounds.

\begin{tabular}{|c|c|c|}
\hline Groups of research & Term of healing, days & Rumen area at $60^{\text {th }}$ day, $\mathrm{cm}^{2}$ \\
\hline Control group (no treatment) & $59.1 \pm 2.3$ & $4.5 \pm 1.9$ \\
\hline AMSC without necrectomy and application of wound dressings & $57.4 \pm 1.9$ & $3.0 \pm 1.1$ \\
\hline AMSC after necrectomy and application of chitosan-copolyamide wound dressings & $44.3 \pm 1.2[1-3]$ & $1.2 \pm 0.7$ \\
\hline AMSC after necrectomy and application of hyaluronic acid wound dressings & $47.2 \pm 1.5[1-2]$ & $0.8 \pm 0.9$ \\
\hline Necrectomy and application of chitosan-copolyamide wound dressings & $51.7 \pm 1.7[1]$ & $2.5 \pm 1.5$ \\
\hline Necrectomy and application of hyaluronic acid wound dressings & $54.2 \pm 1.1$ & $2.0 \pm 1.3$ \\
\hline
\end{tabular}

Note:

a) Significant $(\mathrm{p}<0.05)$ in comparison with the control group (without treatment);

b) Significant $(\mathrm{p}<0.05)$ in comparison with the results of the introduction of AMSC without necrectomy and application of wound dressings;

c) Significant $(\mathrm{p}<0.05)$ in comparison with results of performance of a necrectomy with application of wound dressings of hyaluronic acid without AMSC: Adipo- Genic Mesenchymal Stem Cells.

Table 2 summarizes the histological examination of wound biopsy samples obtained on day 60 . The highest number of blood vessels in the microvasculature in granulation tissue (37 microvessels in the field of vision) was observed in the animals treated with necrectomy, ATMSCs, and hyaluronic acid-based dressings $(\mathrm{p}<0.05)$. Those treated with necrectomy, AT- MSCs, and dressings based on chitosan-copolyamide had 26 microvessels, 3.6 times the number for the animals treated only with ATMSCs without dressings $(\mathrm{p}<0.05)$. The application after necrectomy

Table 2: Number of vessels of microcirculatory bed in granulation tissue at $60^{\text {th }}$ day.

\begin{tabular}{|c|c|}
\hline Groups of research & The number of microvessels, units in sight \\
\hline Control group (no treatment) & $13 \pm 1$ \\
\hline AMSC without necrectomy and application of wound dressings & $10 \pm 2$ \\
\hline AMSC after necrectomy and application of chitosan-copolyamide wound dressings & $26 \pm 3[1-2]$ \\
\hline AMSC after necrectomy and application of hyaluronic acid wound dressings & $37 \pm 4[1-3]$ \\
\hline Necrectomy and application of chitosan-copolyamide wound dressings & $26 \pm 3[1-2]$ \\
\hline Necrectomy and application of hyaluronic acid wound dressings & $28 \pm 1[1-2]$ \\
\hline
\end{tabular}

Note:

a) Significant $(\mathrm{p}<0.05)$ in comparison with the control group (without treatment);

b) Significant $(\mathrm{p}<0.05)$ in comparison with the results of the introduction of AMSC without necrectomy and application of wound dressings;

c) Significant $(\mathrm{p}<0.05)$ in comparison with results of performance of a necrectomy with application of wound dressings of hyaluronic acid without AMSC: Adipogenic Mesenchymal Stem Cells.

Table 3: Thickness of newly formed granulations at the $7^{\text {th }}$ day.

\begin{tabular}{|c|c|}
\hline Groups of research & Thickness of fabric, $\mathbf{~ m k m}$ \\
\hline Control group (no treatment) & $1090.4 \pm 149.7$ \\
\hline AMSC without necrectomy and application of wound dressings & $2002.1 \pm 256.2[1-2]$ \\
\hline AMSC after necrectomy and application of chitosan-copolyamide wound dressings & $1810.1 \pm 181.5[1-2]$ \\
\hline AMSC after necrectomy and application of hyaluronic acid wound dressings & $1783.3 \pm 195.7[1-2]$ \\
\hline Necrectomy and application of chitosan-copolyamide wound dressings & $1676.2 \pm 166.8[1]$ \\
\hline Necrectomy and application of hyaluronic acid wound dressings & $1273.4 \pm 151.3$ \\
\hline
\end{tabular}


Note:

a) Significant $(\mathrm{p}<0.05)$ in comparison with the control group (without treatment);

b) Significant $(\mathrm{p}<0.05)$ in comparison with results of performance of a necrectomy with application of wound dressings of hyaluronic acid without AMSC: Adipo- Genic Mesenchymal Stem Cells

The greatest thickness $(2002.1 \mu \mathrm{m})$ was observed in the group of animals treated with ATMSCs without necrectomy. Using ATMSCs in combination with the natural polymer dressings resulted in granulation tissue an average of 1.66 times thicker than that of the control group ( $p<0.05$ ). The application of only chitosan- copolyamide-based wound dressings after necrectomy resulted in the newly formed granulation tissue being $1676.2 \mu \mathrm{m}$ thick, which was 35\% thicker than that of the control group animals. A microbiological study of wound discharge on day 7 found the minimum level of microorganism vegetation in the group of animals treated with necrectomy, ATMSCs, and wound dressings based on chitosan-copolyamide (Table 4). Moderate growth of pathogenic microflora was observed in the animals treated with necrectomy, ATMSCs, and dressings based on hyaluronic acid as well as in those treated only with the application of the dressings. The highest growth of microflora was observed in those treated with ATMSCs without necrectomy.

Table 4: Number of colony forming units in wound exudate on day 7 (nutrient medium-blood agar) translation.

\begin{tabular}{|c|c|}
\hline Groups of research & Growth of microflora, in + \\
\hline Control group (no treatment) & +++ \\
\hline AMSC without necrectomy and application of wound dressings & +++ \\
\hline AMSC after necrectomy and application of chitosan-copolyamide wound dressings & + \\
\hline AMSC after necrectomy and application of hyaluronic acid wound dressings & ++ \\
\hline Necrectomy and application of chitosan-copolyamide wound dressings & ++ \\
\hline Necrectomy and application of hyaluronic acid wound dressings & ++ \\
\hline
\end{tabular}

Note: The growth of microorganisms: + - weak, ++ - moderate, +++ - significant, ++++ - intensive: Adipogenic Me-Senchymal Stem Cells.

The first stage of the clinical study involved an in-depth assessment of the efficacy and safety of the local application of the CCCPTM gel with ATMSCs to the dermal burn zone. The time taken until the final healing of the burn wounds was one of the primary integral indicators of the efficacy of the treatment. Table 5 presents the results of planimetric estimates of the time of epithelialization of the dermal burns with the application of the gel with ATMSCs at vari- ous concentrations. These results indicate the high efficiency of the gel, showing that the double local use of the gel with ATMSCs at various concentrations shortened the healing period for second- or third-degree burns by 49\%-53\% ( $p<0.01$ ). There was no significant difference in the healing time between the concentrations of 0.05 and $0.1 \mathrm{ml} / \mathrm{cm}^{2}$ of CCCPTM gel. When the gel was used, the epithelization of the dermal burns was completed by day 5-6, which was 59\% shorter than the time taken in the group of patients treated with Ointment Levomekol (10-11 days, $\mathrm{p}<0.05)$.

Table 5: Timing of healing of dermal burn wounds in case of the application of gel with AMSC.

\begin{tabular}{|c|c|}
\hline Groups of research & $\begin{array}{c}\text { Term of healing, day / The period of } \\
\text { healing, the day }\end{array}$ \\
\hline Levomecol ointment & $10.1 \pm 2.7$ \\
\hline CCCP gel $\left(0.05 \mathrm{ml}\right.$ per $\left.1 \mathrm{~cm}^{2}\right)$ & $5.2 \pm 1.5[1]$ \\
\hline CCCP gel $\left(0.1 \mathrm{ml}\right.$ per $\left.1 \mathrm{~cm}^{2}\right)$ & $4.8 \pm 1.2[1]$ \\
\hline
\end{tabular}

Note:

a) Significant $(p<0.05)$ in comparison with the use of the levomecol ointment: Adipogenic Mesenchymal Stem Cells: Collagen Cell Complex Product.
Suppuration frequently occurs when a burn is contaminated with any of a wide range of pathogenic microorganisms (Figure 2). When CCCPTM gel was used, only two cases $(<10 \%)$ experienced a complicated course of the wound process. In comparison, the development of suppurative inflammation of the dermal wounds was observed in almost $40 \%$ of cases treated with Ointment Levomekol. In the second stage of research, MMSCTM at a dose of $0.05 \mathrm{ml} / \mathrm{cm}^{2}$ was used for infiltrative administration into deep burns zones after early necrectomy with simultaneous autodermografting. We present three clinical cases.

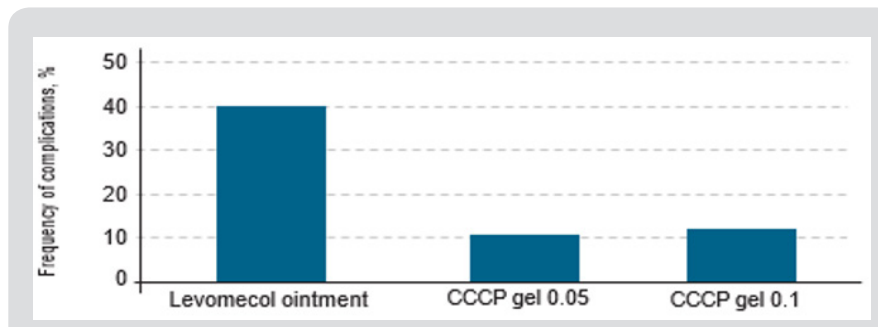

Figure 2: The frequency of purulent inflammation in case of injection of gel with AMSC (Adipogenic Mesenchymal Stem Cells): CCCP-collagen cell complex product.

\section{Case 1}

A 49-year-old patient was hospitalized because of deep burns of the lower extremity covering $6 \%$ of the Body Surface Area (BSA). Early radical necrectomy of the fascia was performed on day 2 after the injury, followed by single-step autodermografting. ATMSCs were administered to an area of up to $1.5 \%$ BSA. At the time of the first dressing, there was no lysis and the autografts showed complete engraftment (Figure 3). 

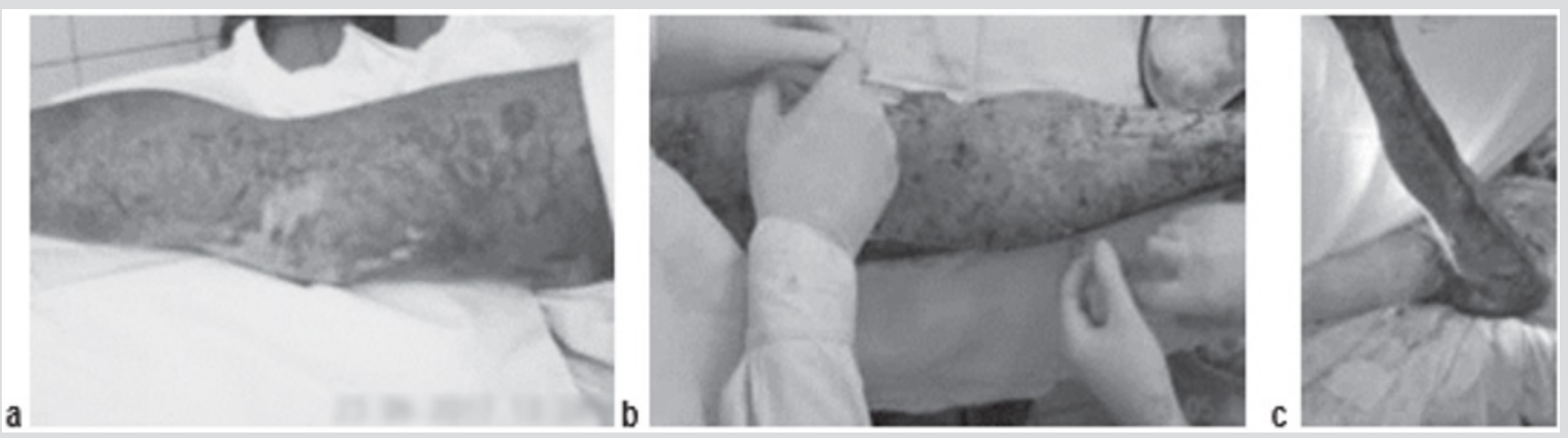

Figure 3: Patient B., 37 years old, burn with a flame of 78\% (67\%)/IIIa-b degree of the head, trunk, extremities:

a) The third day after the burn, before the operation;

b) Intraoperative injection of AMSC after necrectomy and autodermoplasty;

c) Graft on the first dressing.

\section{Case 2}

A 34-year-old severely burned patient, flame burn of $78 \%$ (67 $\%)$ of IIIa, b degree of trunk, limbs. The patient had also suffered a first-degree inhalation injury, and the third-degree burn had resulted in sepsis shock. On day 3, fascial necrectomy of the lower extremity was performed on an area of $15 \%$ BSA, with single-stage autodermografting and the ad- ministration of ATMSCs in the lesion area across $5 \%$ BSA. In the postoperative period, severe sepsis developed, with significant disorders of homeostasis and refractory hypothermia (to $32^{\circ} \mathrm{C}-33^{\circ} \mathrm{C}$ ). Despite these adverse conditions, there was no lysis and the auto- dermal grafts showed engraftment (Figure 4).
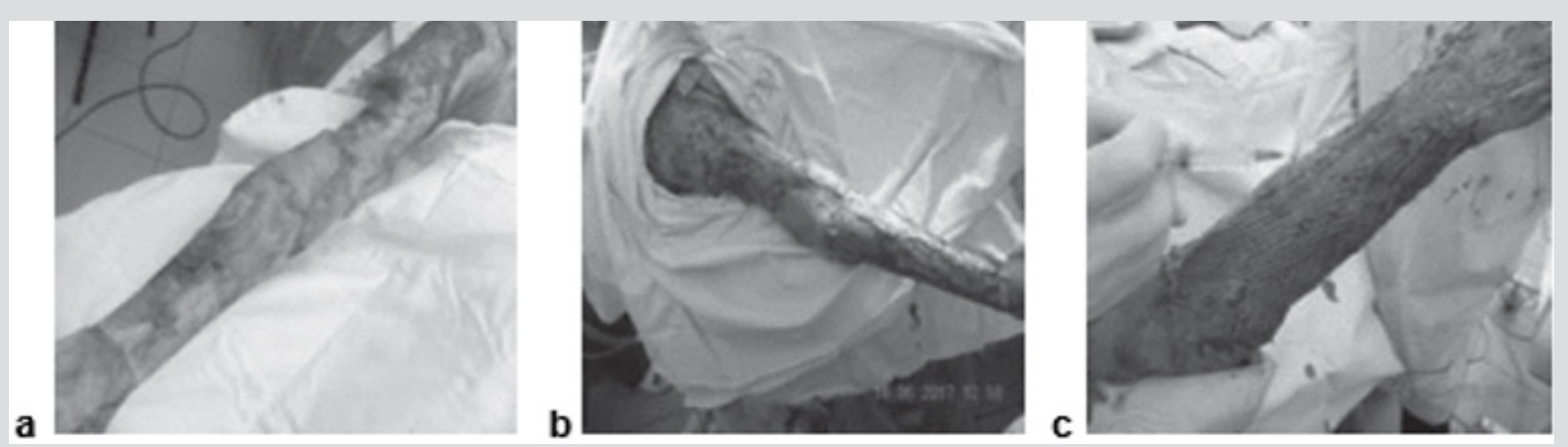

Figure 4: Patient B., 46 years old, flame burn 36\% (16\%)/IIIa, b degree of the head, neck, trunk, upper limbs:

a) The third day after the burn, early surgical necrectomy;

b) Intraoperative injection of AMSC after necrectomy and autodermoplasty;

c) Graft on the first dressing.

\section{Case 3}

A 46-year-old patient was hospitalized because of flame burns of $36 \%$ (16\%)/III a, b degree of the head, neck, torso, and upper extremities. The patient suffered sepsis shock from the thirddegree burns and was resuscitated from clinical death (Figure 5). The general condition of the patient from the time of admission was extremely severe because the aspects of medical care at the prehospital stage, postresuscitation disease, postponement of antishock therapy, and early development of multiple organ failure. The wounds showed as exposed, painful dermis with whitish-gray, in places brown, eschar, which lacked pain sensitivity. Decompression necrectomy of the upper extremities was performed. Under resuscitation conditions, the patient underwent catheterization of the central vessels, intensive in- fusion-transfusion therapy, correction of the water-electrolyte balance, and antibacterial, antisecretory, anticoagulant, metabolic, and symptomatic therapy. In addition, nutritional support and dressings with antiseptic solutions were provided, and a fluidizing unit was applied. On day 2 , early fascial necrectomy of $8 \%$ BSA was performed in the area of the right upper limb with single-stage autodermografting on an area of $5 \%$ BSA with a perforation ratio of $1: 3$ and a subfascial injection of a suspension of allogeneic MSCs $(20 \times 106$ cells in 20 $\mathrm{ml})$. 


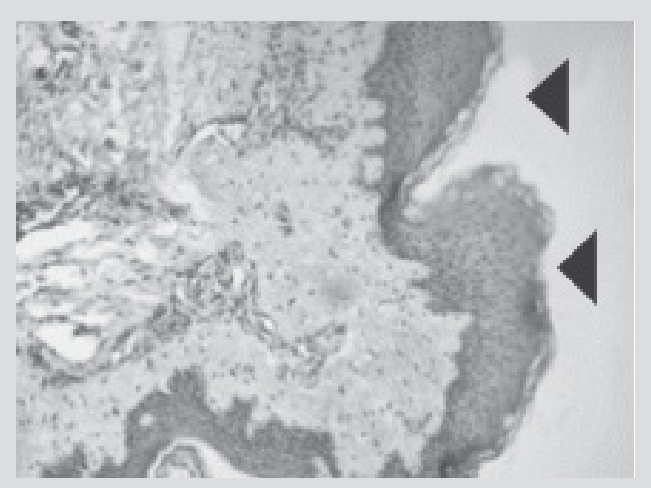

Figure 5: Patient D., 34 year sold, $5^{\text {th }}$ day of observation. Active marginal epithelization. A wide band of the forming epi- dermal layer. Color in gof hematoxylin-eosin. Zoom $\times 400$.

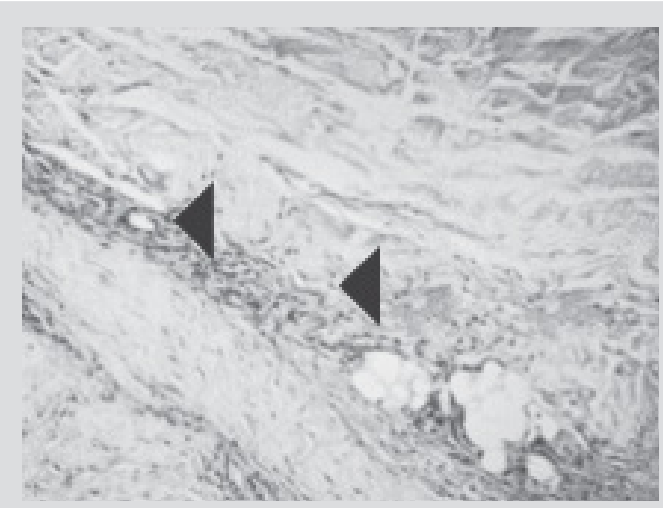

Figure 6: Patient E., 49 years old, $5^{\text {th }}$ day of observation. Newly formed vessels with perifocal proliferation of fibroblasts. Color in gof hematoxylin-eosin. Zoom $\times 400$.

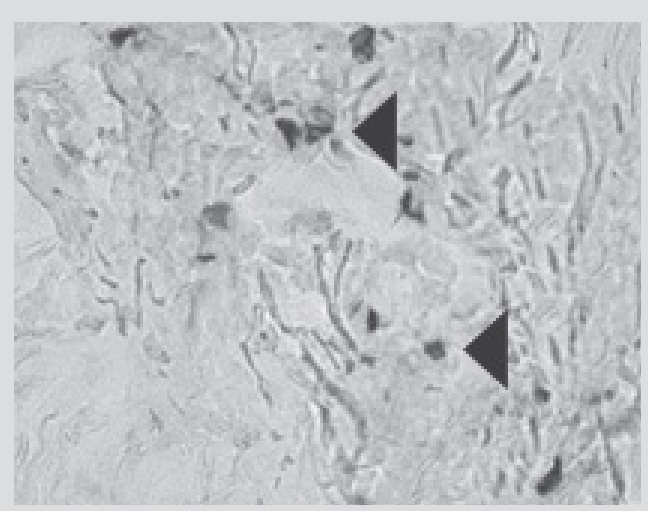

Figure 7: Patient D., 34 years old. Significant expression of the proliferation marker of Ki 67 cells of an autologous $\mathrm{cu}$ - taneous graft on the $5^{\text {th }}$ day after the AMSC injection. Zoom $\times 600$.

The same dose of allogeneic MSCs was administered into the zone of primary transplantation at the first dressing and on day 5 after the injury. In the postoperative period, there was no lysis and $100 \%$ engraftment of autodermal grafts. The patient died because of the severity of the injury, aspects of care, clinical death experienced at the prehospital stage, progression of multiple organ failure, and development of septic shock. The death was not associated with the successful recovery of the skin area. Histological examination of biopsy samples taken from the area of ATMSC transplantation for all the patients revealed the presence of pronounced vascularization with the perifocal proliferation of fibro- blasts in both the superficial and deep layers of the dermis (Figures 6 \& 7). An immunohistochemical study revealed that the use of ATMSCs resulted in a 5.6- fold increase in the expression of proliferation markers of epithelial and connective tissue cell lines in the injection area $(\mathrm{p}<0.01)$ (proliferation 2.1-2.2), and that apoptotic activity was completely suppressed (Figure 8).

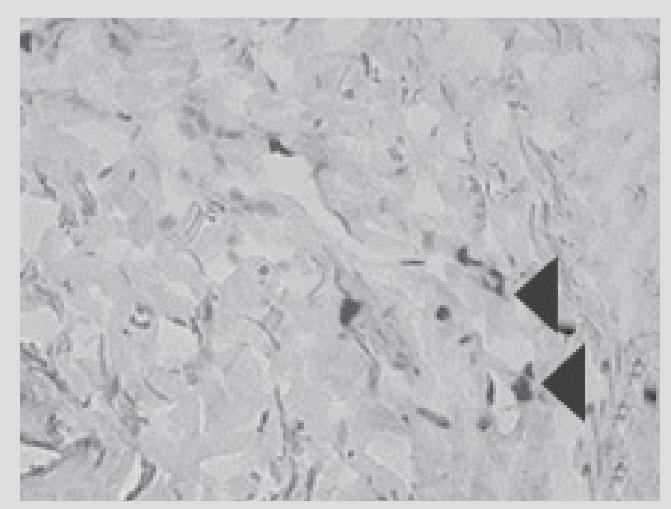

Figure 8: Patient E., 49 years old. Significant expression of the proliferation marker of Ki 67 cells of an autologous $\mathrm{cu}$ - taneous graft on the $5^{\text {th }}$ day after the AMSC injection. Zoom $\times 600$.

Laser Doppler flowmetry assessment of the microcirculation in the area of stem cell injection on day 7 after early necrectomy, skin grafting, and the administration of MMSCTM showed double the average level of perfusion and mean square deviation of the amplitude of blood flow oscillations than for areas where MMSCTM was not used $(p<0.05)$ (Table 6). These findings showed that the use of cellular preparations containing ATMSCs was a promising method for treating patients with dermal and deep burns. Using CCСPTM gel accelerated the processes of reparative regeneration in wounds by $59 \%(\mathrm{p}<0.05)$ and the frequency of infectious complications decreased by $41 \%(\mathrm{p}<0.05)$. The histological, immunohistochemical, and floumetric findings showed that the administration of MMSCTM suspension to patients with deep burns reliably stimulated the proliferation of fibro-blasts and angiogenesis in the area of the lesions. Including the administration of ATMSCs in clinical practice should improve the results of treatment of patients with burns. 
Table 6: Intensity of microcirculation in the area of MMCS injection.

\begin{tabular}{|c|c|c|}
\hline Groups of research & Term of healing, days & Rumen area at $60^{\text {th }}$ day, $\mathrm{cm}^{2}$ \\
\hline Control group (no treatment) & $59.1 \pm 2.3$ & $4.5 \pm 1.9$ \\
\hline AMSC without necrectomy and application of wound dressings & $57.4 \pm 1.9$ & $3.0 \pm 1.1$ \\
\hline $\begin{array}{c}\text { AMSC after necrectomy and application of chitosan-copolyamide wound } \\
\text { dressings }\end{array}$ & $44.3 \pm 1.2[1-3]$ & $1.2 \pm 0.7$ \\
\hline AMSC after necrectomy and application of hyaluronic acid wound dressings & $47.2 \pm 1.5[1-2]$ & $0.8 \pm 0.9$ \\
\hline Necrectomy and application of chitosan-copolyamide wound dressings & $51.7 \pm 1.7[1]$ & $2.5 \pm 1.5$ \\
\hline Necrectomy and application of hyaluronic acid wound dressings & $54.2 \pm 1.1$ & $2.0 \pm 1.3$ \\
\hline
\end{tabular}

Note: ПM-microcirculation index; $\delta$-mean square deviation of blood flow fluctuation amplitude; KV-the coefficient of variation: Adipogenic Mesenchymal Stem Cells.

\section{Conclusion}

The preliminary results obtained in this study provide convincing evidence that the administration of ATMSCs can increase the efficacy of the local treatment of superficial burn wounds as well as enhancing the surgical restoration of skin with deep burns. In the animal experiment, the greatest efficacy (measured by the time taken to heal) was observed in the treatment of deep skin burns with necrectomy, the administration of ATMSCs, and the application of dressings based on aliphatic copolyamide and chitosan. In the animals treated in this way, the healing time decreased by $89.6 \%$ $(p<0.05)$ compared with that of the control group. In the animals treated with necrectomy and wound dressings based on aliphatic copolyamide and chitosan, but without use of ATMSCs, the healing time was reduced by only $25 \%$ compared with the control group ( $p>0.05)$. The smallest area of scarring $\left(0.8 \mathrm{~cm}^{2}\right)$ was ob- served in the animals treated with stem cells and wound dressing based on hyaluronic acid. The application of dressings from natural polymers without administering stem cells reduced the total area of scarring to $2 \mathrm{~cm}^{2}$, which was $56 \%$ smaller than that of the control group $\left(4.5 \mathrm{~cm}^{2} ; \mathrm{p}<0.05\right)$.

In the microbiological estimates of the number of colonyforming units of microorganisms in wounds on day 7 of the experiment, the fewest colony-forming units were recorded in the animals treated with necrectomy, ATMSCs, and wound dressings based on polymers. In the animals treated with necrectomy and the subsequent closure of the wounds with hyaluronic acid or chitosan-copolyamide, without ATMSC treatment, the number of colony-forming units of pathogenic microflora did not exceed $30 \%$. The histological examination of wound biopsy samples from the animals found the greatest development of the microvasculature bed by the end of the fourth week in the animals treated with necrectomy, ATMSCs, and dressings based on hyaluronic acid. In these animals, 37 microvessels were counted in the field of vision, which was 3.7 times the number ob- served when the treatment was with ATMSCs alone $(\mathrm{p}<0.05)$. The findings of the experimental studies suggested that the use of ATMSCs with wound dressings based on natural polymers provided highly efficient treatment for burns. This may benefit from further research in this field including the development of tissue-engineering structures with living cells.
The clinical study of the efficacy of the CCCPTM gel showed that its application reduced not only the healing time of dermal burns but also incidence of infectious complications. Applying the allogeneic mesenchymal stem cell gel at the two concentrations investigated in this study accelerated the epithelization of burns degree II and IIIa, which was established by day 5 (about half the time taken in the comparison group), and the frequency of complications of the wound process did not exceed $10 \%$ of cases (compared with $40 \%$ in the control group). The positive properties of MMSCTM result from the ability of its constituent ATMSCs to differentiate into cells of tissues of mesenchymal origin and other germ layers. The ATMSCs produce cytokines, including interleukins, growth factors, fibronectin, type I and IV collagen, laminin, thromboplastin, and other substances. The overall effect of this is normalization of the expression of proinflammatory cytokines, stimulation of the production of growth factors, reduction of the activity of matrix metalloproteinase 9 , and, as a result, the stimulation of the regeneration of damaged tissues and scar formation. This cell type also has immunosuppressive properties and high histocompatibility [39].

The results of the clinical evaluation of the efficacy of the MMSCTM preparation demonstrated that its administration into a deep burn zone after performing early necrectomy and single-stage autodermografting accelerated the formation of blood vessels in the newly formed tissues, increased the incidence of engraftment of the split skin graft, stimulated the epithelialization of the wound surface, and optimized the reparative regeneration processes. The preparation did not cause any adverse events or changes in clinical, biochemical, blood test, or urine analysis results. In conclusion, the preparations containing ATMSCs (CCCPTM gel and MMSCTM suspension) can significantly improve the results of the treatment of patients with dermal and deep burn lesions.

\section{References}

1. Alekseev AA (2010) Organizatsiya meditsinskoy pomoshchi postradavshim from ozhogov v rossiyskoy federatsii. In: Proceedings of the $9^{\text {th }}$ congress of traumatologists-orthopedists of Russia. Saratov, 1517 Saratov, p. 15-16.

2. Podoynitsyna MG, Tsepelev VL, Stepanov AV (2015) The use of physical methods in the treatment of the skin burn. Modern problems of science and education 5 . 
3. Zuk PA, Zhu M, Ashjian P, De Ugarte DA, Huang JI, et al. (2002) Human adipose tissue is a source of multipotent stem cells. Mol Biol Cell 13(12): 4279-4295.

4. Zuk PA, Zhu M, Mizuno H, Huang J, Futrell JW, et al. (2001) Multilineage cells from human adipose tissue: implications for cell-based therapies. Tissue Eng 7(2): 211-228.

5. Kiseleva EP, Gain MY (2013) Effectiveness of use of mesenchymal stem cells of the adipose tissue for skin defect restoration in experiment. Vestnik Natsional'noy akademii nauk Belorussii. Seriya "Meditsinskie nauki" 2: 75-81.

6. Zhu X, Shi W, Tai W, Liu F (2012) The comparition of biological characteristics and multilineage differentiation of bone marrow and adipose derived Mesenchymal stem cells. Cell Tissue Res 350(2): 277 287.

7. Timper K, Seboek D, Eberhardt M, Linscheid P, Christ-Crain M, et al. (2006) Human adipose tissue-derived mesenchymal stem cells differentiate into insulin, somatostatin, and glucagon expressing cells. Biochem Biophys Res Commun 341(4): 1135-1140.

8. Nikolsky NN, Gabay IA, Somova NV (2007) Human embryonic stem cells. Problems and prospects. Tsitologiia 49(7): 529-537.

9. Cavallari G, Olivi E, Bianchi F, Ventura C, Nardo B, et al. (2012) Mesenchymal stem cells and islet cotransplantation in diabetic rats: improved islet graft revascularization and function by human adipose tissue-derived stem cells preconditioned with natural molecules. Cell Transplant 21(12): 2771-2781.

10. Kang Y, Park C, Kim D, Kwon K, Choi C, et al. (2010) Unsorted human adipose tissue-derived stem cells promote angiogenesis and myogenesis in murine ischemic hindlimb model. Microvasc Res 80(3): 310-316.

11. Seo MJ, Suh SY, Bae YC, Jung JS (2005) Differentiation of human adipose stromal cells into hepatic lineage in vitro and in vivo. Biochem Biophys Res Commun 328(1): 258-264.

12. Planat-Benard V, Silvestre JS, Cousin B (2004) Plasticity of human adipose lineage cells toward endothelial cells: physiological and therapeutic perspectives. Circulation. 109(5): 656-663.

13. Muehlberg FL, Song YH, Krohn A, Pinilla SP, Droll LH, et al. (2009) Tissueresident stem cells promote breast cancer growth and metastasis. Carcinogenesis 30(4): 589-597.

14. E. Nagwa (2017) Advances in Stem Cell Therapy. Bench to Bedside. Cham: Humana Press.

15. Liu P, Deng Z, Han S, Liu T, Wen N, et al. (2008) Tissue-engineered skin containing mesenchymal stem cells improves burn wounds. Artif Organs 32(12): 925-931.

16. Pittenger MF, Alastair M Mackay, Stephen C Beck, Rama K Jaiswal, Robin Douglas, et al. (1999) Multilineage Potential of Adult Human Mesenchymal Stem Cells. Sciencen 284(5411): 143-147.

17. Baranov EV, Tretyak SI, Vasilevich IB (2013) The clinical application of autologous mesenchimal stem cells isolated from fat tissue for the treatment of patients with trophic ulcers of lower extremities. Cellular transplantology and tissue engineering 8(2): 79-84.

18. Bondarenko NA, Lykov AP, Kazakov OV (2017) Changes in functional properties of mesenchymal stem cells under the influence of erythropoietin. Modern problems of science and education 6 .

19. Zinovev EV, Tsygan VN, Asadulaev MS (2017) Experimental evaluation of the effectiveness of adipogenic mesenchymal stem cells for the treatment of skin burns of III degree. Vestnik Rossiiskoi voenno meditsinskoi akademii 1:137-141.

20. Mitchell JB, McIntosh K, Zvonic S, Garrett S, Floyd ZE, et al. (2006) Immunophenotype of human adipose-derived cells: temporal changes in stromal-associated and stem cell-associated markers. Stem Cells 24(2): 376-385.
21. Tse WT, Pendleton JD, Beyer WM, Egalka MC, Guinan EC (2003) Suppression of allogeneic T-cell proliferation by human marrow stromal cells: implications in transplantation. Transplantation 75(3): 389-397.

22. Bassi EJ, Moraes Vieira PM, Moreira-Sa CS, Almeida DC, Vieira LM, et al. (2012) Immune regulatory properties of allogeneic adiposederived mesenchymal stem cells in the treatment of experimental autoimmune diabetes. Diabetes 61(10): 2534-2545.

23. Kuo YR, Chen CC, Goto S, Lee IT, Huang CW, et al. (2011) Modulation of immune response and T-cell regulation by donor adipose-derived stem cells in a rodent hind-limb allotransplant model. Plast Reconstr Surg 128(6): 661e-672e.

24. Meza-Zepeda LA, Noer A, Dahl JA, Micci F, Myklebost O, et al. (2008) High-resolution analysis of genetic stability of human adipose tissue stem cells cultured to senescence. J Cell Mol Med 12(2): 553-563.

25. Yanez R, Lamana ML, Garcia-Castro J, Colmenero I, Ramirez M, et al. (2006) Adipose tissue-derived mesenchymal stem cells have in vivo immunosuppressive properties applicable for the control of the graftversus-host disease. Stem Cells 24(11): 2582-2591.

26. Cui L, Yin S, Liu W, Cao Y, Li N, et al. (2007) Expanded adipose-derived stem cells suppress mixed lymphocyte reaction by secretion of prostaglandin E2. Tissue Eng 13(6): 1185-1195.

27. Gimble JM, Katz AJ, Bunnell BA (2007) Adipose-derived stem cells for regenerative medicine. Circ Res 100(9): 1249-1260.

28. Gonzalez-Rey E, Gonzalez MA, Varela N, O Valle F, Hernandez-Cortes P, et al. (2010) Human adipose-derived mesenchymal stem cells reduce inflammatory and $\mathrm{T}$ cell responses and induce regulatory $\mathrm{T}$ cells in vitro in rheumatoid arthritis. Ann Rheum Dis 69(1):241-248.

29. Niemeyer P, Vohrer J, Schmal H, Kasten P, Fellenberg J, et al. (2008) Survival of human mesenchymal stromal cells from bone marrow and adipose tissue after xenogenic transplantation in immunocompetent mice. Cytotherapy 10(8): 784-795.

30. Puissant B, Barreau C, Bourin P, André M, Nibbelink M, et al. (2005) Immunomodulatory effect of human adipose tissue-derived adult stem cells: comparison with bone marrow mesenchymal stem cells. Br J Haematol 129(1): 118-129.

31. Safford KM, Hicok KC, Safford SD, Halvorsen YD, Wilkison WO, et al. (2002) Neurogenic differentiation of murine and human adiposederived stromal cells. Biochem Biophys Res Commun 294(2): 371-379.

32. Kucerova L, Altanerova V, Matuskova M, Tyciakova S, Altaner C (2007) Adipose tissue-derived human mesenchymal stem cells mediated prodrug cancer gene therapy. Cancer Res 67(13): 6304-6313.

33. Kim Y, Kim H, Cho H, Bae Y, Suh K, et al. (2007) Direct comparison of human mesenchymal stem cells derived from adipose tissues and bone marrow in mediating neovascularization in response to vascular ischemia. Cell Physiol Biochem 20(6): 867-876.

34. Alekseeva IS, Volkov AV, Kulakov AA, Goldshtein DV (2012) Clinical and experimental study on the use of combined cell transplant on the basis of multipotent mesenchymal stromal cells of adipose tissue in patients with severe deficiency of jaws bone tissue. Cellular transplantology and tissue engineering 7(1): 97-105.

35. Vengerovich NG, Khripunov AK, Ruzanova EA (2016) Regenerative therapy by tissue-protective cytokines as a component of bacterial cellulose based wound dressings. Vestnik Sankt-Peterburgskogo universiteta. Seriia 11 "Meditsina" 11(1): 36-46.

36. Kotenko KV, Eremin II, Moroz BB, AJu Bushmanov (2012) Cell technologies in the treatment of radiation burns: experience Burnasyan Federal Medical Biophysical Centre. Cellular transplantology and tissue engineering 7(2): 97-102.

37. Xue L, Xu YB, Xie JL, Tang JM, Shu B, et al. (2013) Effects of human bone marrow mesenchymal stem cells on burn injury healing in a mouse model. Int J Clin Exp Pathol 6(7): 1327-1336. 
38. Bryukhovetskyi IS, Bryukhovetskyi AS, Mischenko PV, Khotimchenko YS (2013) The role of systemic migration and homing mechanisms of stem cells in the development of malignant tumors of the centra nervous system and the development of new cancer therapies. Rossiiskii bioterapevticheskii zhurnal 12(4): 3-12.

\section{ISSN: 2574-1241}

DOI: 10.26717/BJSTR.2019.16.002872

EV Zinovye. Biomed J Sci \& Tech Res

(C) This work is licensed under Creative

Submission Link: https://biomedres.us/submit-manuscript.php
39. Akanov ZA (2010) Perspectives of stem cell techniques application in medicine. Meditsina i ekologiya 2.

$\begin{array}{ll}\text { BIOMEDICAL } & \text { Assets of Publishing with us } \\ \text { RESEARCHES } & \text { - Global archiving of articles } \\ & \text { - Immediate, unrestricted online access } \\ & \text { - Rigorous Peer Review Process } \\ \end{array}$

